\title{
Antimicrobial, Cytotoxic, Thrombolytic and Antioxidant Activities of Syzygium fruticosum (Roxb.) DC.
}

\author{
Somaia Haque Chadni ${ }^{1}$, Abdullah Al Hasan ${ }^{2}$ and A.T.M. Zafrul Azam ${ }^{1}$ \\ ${ }^{1}$ Department of Pharmaceutical Chemistry, Faculty of Pharmacy, University of Dhaka, Dhaka-1000, Bangladesh \\ ${ }^{2}$ Department of Pharmacy, Southeast University, Dhaka-1213, Bangladesh
}

\begin{abstract}
The crude methanol extracts of the bark and leaves of Syzygium fruticosum (Roxb.) DC. were partitioned with petroleum ether, carbon tetrachloride, chloroform and water for biological investigation. In the brine shrimp lethality bioassay, carbon tetrachloride soluble fraction of leaf extract (LCTF) showed significant lethality having the $\mathrm{LC}_{50}$ value $0.65 \mu \mathrm{g} / \mathrm{ml}$. In free radical scavenging activity screening (DPPH assay), chloroform fraction of methanolic extract of bark of $S$. fruticosum showed the highest free radical scavenging activity with $\mathrm{IC}_{50}$ value $20.01 \mu \mathrm{g} / \mathrm{ml}$. In the microbiological investigation, only chloroform soluble fraction of bark (BCF) and aqueous fraction of bark (BAF) showed mild antimicrobial activity with zone of inhibition ranging from 7 to $14 \mathrm{~mm}$ as compared to standard ciprofloxacin (zone of inhibition of $50 \mathrm{~mm}$ ). In the study for thrombolytic property, different extracts of $S$. fruticosum revealed varying degrees of thrombolytic activity ranging from $33.46 \%$ to $62.51 \%$.
\end{abstract}

Key words: Syzygium, antimicrobial, brine shrimp lethality, free radical scavenging, thrombolytic activity.

\section{Introduction}

Syzygium fruticosum is a flowering plant of the Myrtaceae family. This family encompasses plants whose characteristics are of high industrial, pharmaceutical, scientific, and cultural importance. It is found in India, Myanmar, Thailand, China, Bangladesh and some other Asian countries. Traditionally, it is used as folk remedy for the treatment of stomachic, diabetes and bronchitis (Ruan et al., 2008; Jain et al., 2010).

Literature review showed that different species of Syzygium possess a variety of biological activities. The leaves of $S$. cumini revealed anti-allergic, antioxidant, anti-inflammatory and analgesic properties (Ruan et al., 2008; Jain et al., 2010). The fruit and bark extracts of $S$. aromaticum and the seed extracts of $S$. aqueum, $S$. aromaticum and $S$. jambos showed antioxidant, antiallergic, antidiabetic, antihyperlipidemic, gastroprotective and analgesic activities (Muruganandan et al., 2001; Ruan et al., 2008; Jain et al., 2010; Singh and Gupta, 2007; Ravi et al., 2004; Kasiappan et al., 2005). Many Syzygium species showed $\alpha$-glucosidase inhibitory activity (Omar $e t$ al., 2012), antihyperlipidemic effect (Sharma et al., 2011), antiatherosclerotic potential (Tanwar et al., 2011), antibacterial activity (Machado et al., 2005), anti-HIV activity (Kusumoto et al., 1995) and so on. The seed extracts of $S$. fruticosum displayed antioxidant and anticancer properties (Islam et al., 2013).

On the other hand, chemical investigations of Syzygium species have revealed the presence of flavonoids, gallic acid, ellagic acid, glycosides triteripenoids and saponins (Bhatia and Bajaj, 1975). $\beta$-sitosterol, betulinic acid, mycaminose, crategolic (maslinic) acid, $n$-hepatcosane, n-nonacosane, $n$-hentriacontane, noctacosanol, $n$-triacontanol, $n$-dotricontanol, quercetin, myricetin, myricitrin and the flavonol glycosides myricetin 3-O-(4"-acetyl)- $\alpha$-Lrhamnopyranosides, acylated flavonol glycosides have been isolated from the leaves of $S$. cumini (Mahmoud et al., 2001; Sagrawat et al., 2006). However, until now no phytochemical studies of $S$. fruticosum could be found in literature.

The present work was an endeavor to screen the methanolic extract (ME) of $S$. fruticosum and its different fractions for probable antibacterial, cytotoxic, thrombolytic and antioxidant activities, and we, here in, report the results of our preliminary investigations.

Correspondence to: A.T.M. Zafrul Azam, Tel. +880-1710-880064; Fax: +880-2-8615583; E-mail: zafrulazam@du.ac.bd 


\section{Materials and Methods}

Plant material: Whole plant of S. fruticosum (Roxb.) DC. was collected from Debidwar, Comilla, Bangladesh in the month of August, 2009, and was identified at the Department of Botany, University of Dhaka, Bangladesh.

Extraction: The powdered leaf and bark (1000 g) of $S$. fruticosum were separately soaked in methanol $(4 \mathrm{~L})$ for 15 days. Solvent-solvent partitioning of the residues were done by using the protocol designed by Kupchan and modified by VanWagenen et al. (1993). For bioassay the crude extract of bark and leaf (5gm each) was separately dissolved in $10 \%$ aqueous methanol and partitioned by using petroleum ether, carbon tetrachloride and chloroform leaving an aqueous soluble material. The fractions were designated as $\mathrm{BPF}, \mathrm{BCTF}, \mathrm{BCF}$ and $\mathrm{BAF}$ from bark and LPF, LCTF, LCF and LAF from leaf, respectively.

Antimicrobial activity: The samples were tested for antimicrobial activity by the standardized disc diffusion method (Bauer et al., 1966). The screening was done against some strains of bacteria. The results thus obtained were compared with standard antibiotic, ciprofloxacin.

Cytotoxicity screening: In brine shrimp lethality bioassay (Meyer et al., 1982) dimethyl sulfoxide (DMSO) was used as solvent as well as negative control while vincristine sulfate (VS) served as the positive control. For cytotoxicity screening, DMSO solutions of the test samples were applied against Artemia salina in a 1-day in vivo assay. For the experiment, $4 \mathrm{mg}$ of each of the test samples was dissolved in DMSO and solutions of varying concentrations $(400,200,100,50,25,12.50,6.25,3.125$, $1.563,0.781 \mu \mathrm{g} / \mathrm{ml}$ ) were obtained by serial dilution technique.

Antioxidant activity: The free radical scavenging activity (antioxidant capacity) of the test samples were measured by 1,1-diphenyl-2-picrylhydrazyl (DPPH), the detailed procedure could be found elsewhere (BrandWilliams et al., 1995).

Thrombolytic activity: Following the method developed by Prasad et al. (2007) whole blood was drawn from healthy human volunteers $(n=10)$ without a history of oral contraceptive or anticoagulant therapy and $1 \mathrm{ml}$ of blood was transferred to the previously weighed sterile Eppendorf tubes and was allowed to form clots. After clot formation, the serum was completely removed without disturbing the clot. To each Eppendorf tube containing pre-weighed clot, $100 \mu \mathrm{l}$ aqueous solutions of different extracts along with the crude extracts were added separately. As a positive control, $100 \mu \mathrm{l}$ of streptokinase (SK) and as a negative non thrombolytic control, $100 \mu \mathrm{l}$ of distilled water were separately added to the control Eppendorf tubes. All tubes were then incubated at $37{ }^{\circ} \mathrm{C}$ for 90 minutes and observed for clot lysis. The released fluid was removed and Eppendorf tubes were again weighed to observe the difference in weight after clot disruption. Difference obtained in weight taken before and after clot lysis was expressed as percentage of clot lysis as shown below:

$\%$ clot lysis $=($ Weight of the lysis clot $/$ Weight of clot before lysis) $\times 100$

\section{Results and Discussion}

Antimicrobial activity: Antibacterial activity of all test samples were investigated against five gram positive bacteria namely, Bacillus cereus, B. megaterium, $B$. subtilis, Sarcina lutea \& Staphylococcus aureus and eight gram negative bacteria namely, Escherichia coli, Pseudomonas aeruginosa, Salmonella paratyphi, S. typhi, Shigella boydii, S. dysenteriae, Vibrio mimicus \& V. parahaemolyticus. In this study, the chloroform soluble fraction of bark (BCF) and aqueous soluble fraction of bark (BAF) showed mild to moderate antimicrobial activity with zone of inhibition from 7 to $14 \mathrm{~mm}$ as compared to standard ciprofloxacin, which displayed zone of inhibition of $50 \mathrm{~mm}$. So, these fractions (BCF, BAF) can be further studied to explore potent antimicrobial agents.

Cytotoxicity screening: The median lethal concentration $\left(\mathrm{LC}_{50}\right)$ of the test samples after $24 \mathrm{hr}$ exposure was obtained by a plot of percentage of the shrimps died against the logarithm of the sample concentration. Vincristine sulfate (VS) was used as positive control and the $\mathrm{LC}_{50}$ was found $0.37 \mu \mathrm{g} / \mathrm{ml}$ for VS. Among the extractives of $S$. fruticosum the carbon tetrachloride soluble fraction of leaf extract showed most significant lethality having the $\mathrm{LC}_{50}$ value $0.65 \mu \mathrm{g} / \mathrm{ml}$.

Antioxidant activity: In this investigation, chloroform soluble fraction of methanolic extract of bark showed the highest free radical scavenging activity with $\mathrm{IC}_{50}$ value $20.01 \mu \mathrm{g} / \mathrm{ml}$ (Table 1). 
Table $1 . \mathrm{IC}_{50}$ values of the test samples and standard.

\begin{tabular}{cc}
\hline Test samples & $\mathrm{IC}_{50}(\mu \mathrm{g} / \mathrm{ml})$ \\
\hline Standard & 20.36 \\
BME & 27.35 \\
BPF & 24.35 \\
BCTF & 25.52 \\
BCF & 20.01 \\
BAF & 66.39 \\
LME & 26.84 \\
LPF & 29.74 \\
LCTF & 72.43 \\
LCF & 41.45 \\
LAF & 20.92 \\
\hline
\end{tabular}

The average values of three replicates are presented as mean.

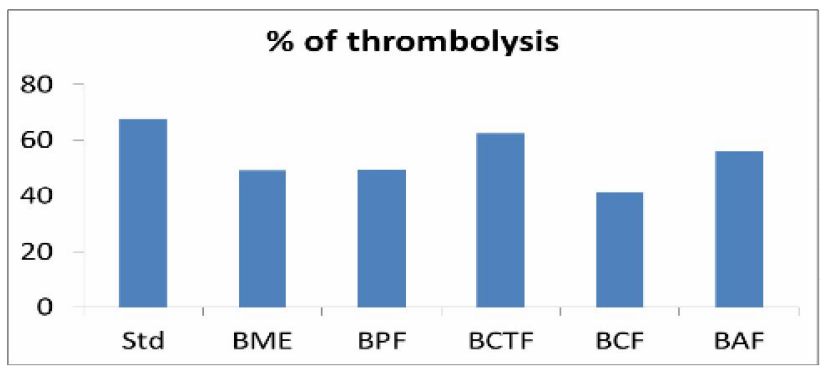

Figure 1. Thrombolytic activity of bark extractives of Syzygium fruticosum.

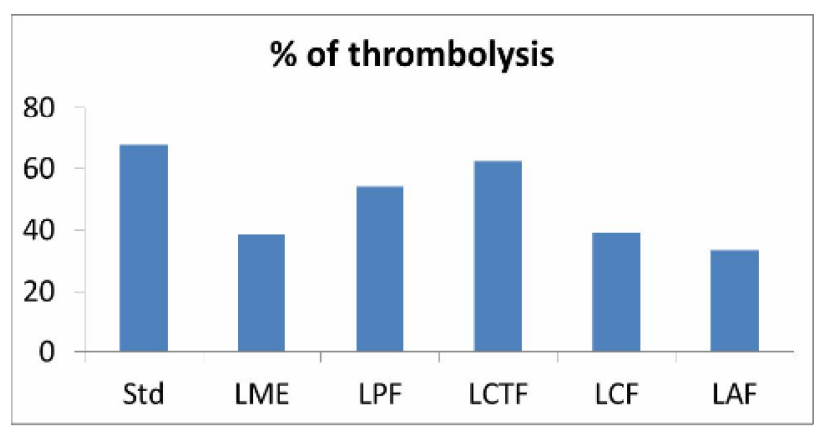

Figure 2. Thrombolytic activity of leaf extractives of Syzygium fruticosum.

Thrombolytic activity: Addition of $100 \mu \mathrm{l}$ SK, a positive control (30,000 I.U.) to the clots and subsequent incubation for 90 minutes at $37^{\circ} \mathrm{C}$, showed $67.67 \%$ lysis of clot. On the other hand, distilled water treated as negative control exhibited a negligible percentage of lysis of clot $(9.14 \%)$. In this study, different test samples of $S$. fruticosum exhibited varying degrees of thrombolytic activity ranging from $33.46 \%$ to $62.51 \%$ (Figure 1 and Figure 2).
Therefore, it can be concluded from the preliminary studies that some of the test samples obtained from $S$. fruticosum revealed mild to moderate antibacterial activity while significant antioxidant, cytotoxic as well as thrombolytic activities.

\section{References}

Bauer, A.W., Kirby, W.M., Sherris, J.C. and Turck, M. 1966. Antibiotic susceptibility testing by a standardized single disc method. Am. J. Clin. Pathol. 45, 493-496.

Bhatia, I.S., and Bajaj, K.L. 1975. Chemical constituents of the seeds and bark of Syzygium cumini. Planta Med. 28, 346352 .

Brand-Williams, W., Cuvelier, M.E. and Berset, C. 1995. Use of a free radical method to evaluate antioxidant activity. $L W T$ Food Sci. Technol. 28, 25-30.

Islam, S., Nasrin, S., Khan, M.A., Hossain, A.S.M.S., Islam, F., Khandokhar, P., Mollah, M.N.H., Rashid, M., Sadik, G., Rahman, M.A.A. and Alam, A.H.M.K. 2013. Evaluation of antioxidant and anticancer properties of the seed extracts of Syzygium fruticosum Roxb. growing in Rajshahi, Bangladesh. BMC Complementary and Alternative Med. 13, 142-151.

Jain, A., Sharma, S., Goyal, M., Dubey, S., Jain, S., Sahu, J., Sharma, A. and Kaushik, A. 2010. Anti-inflammatory activity of Syzygium cumini leaves. Int. J. Phytomed. 2, 124-126.

Kasiappan, R., Subbaih, R. and Subramanian, S. 2005. Antihyperlipidemic effect of Eugenia jambolana seed kernel on streptozotocin induced diabetes rats. Food Chem. Toxicol. 43, 1433-1439.

Kusumoto, I.T., Nakabayashi, T., Kida, H., Miyashiro, H., Hattori, M., Namba, T. and Shimotohno, K. 1995. Screening of various plant extracts used in ayurvedic medicine for inhibitory effects on human immunodeficiency virus type 1 (HIV-1) protease. Phytotherapy Res. 9, 180184.

Machado, K.E., Filho, V.C., Tessarolo, M.L., Mallmann, R., Meyre-Silva, C. and Bella Cruz, A. 2005. Potent antibacterial activity of Eugenia umbelliflora. Pharmaceut. Biol. 43, 636-639.

Mahmoud, I.I., Marzouk, M.S., Moharram, F.A., El-Gindi, M.R., and Hassan, A.M. 2001. Acylated flavonol glycosides from Eugenia jambolana leaves. Phytochemistry 58, 1239-1244.

Meyer, B.N., Ferrigni, N.R., Putnam, J.E., Jacobsen, L.B., Nichols, D.E. and McLaughlin, J.L. 1982. Brine shrimp: a convenient general bioassay for active plant constituents. Planta Med. 45, 31-34. 
Muruganandan, S., Srinivasan, K., Chandra, S., Tandan, S.K., Lal, J. and Raviprakash, V. 2001. Anti-inflammatory activity of Syzygium cumini bark. Fitoterapia 72, 369-375.

Omar, R., Li, L., Yuan, T. and Seeram, N.P. 2012. $\alpha$-Glucosidase inhibitory hydrolyzable tannins from Eugenia jambolana seeds. J. Nat. Prod. 75, 1505-1509.

Prasad, S., Kashyap, R.S., Deopujari, J.Y., Purohit, H.J., Taori, G.M. and Daginawala, H.F. 2007. Effect of Fagonia arabica (Dhamasa) on in vitro thrombolysis. Complement. Alternat. Med. 7, 7- 36.

Ravi, K., Sivagnanam, K. and Subramanjan, S. 2004. Antidiabetic activity of Eugenia jambolana seed kernels on streptozotocin induced diabetic rats. J. Med. Food 7, 187191.

Ruan, P.Z., Zhang, L.L., Lin and M.Y. 2008. Evaluation of the antioxidant activity of Syzygium cumini leaves. Molecules 13, 2545-2556.

Sagrawat, H., Mann, A.S. and Kharya, M.D. 2006. Pharmacological potential of Eugenia jambolana: A review. Pharmacog. Mag. 2, 96-105.
Sharma, S.B., Tanwar, R.S., Nasir, A. and Prabhu, K.M. 2011. Antihyperlipidemic effect of active principle isolated from seed of Eugenia jambolana on alloxan-induced diabetic rabbits. J. Med. Food 14, 353-359.

Singh, N. and Gupta, M. 2007. Effects of ethanolic extract of Syzygium cumini (L.) seed powder on pancreatic islet of alloxan diabetic rats. Ind. J. Exp. Biol. 45, 861-867.

Tanwar, R.S., Sharma, S.B., Singh, U.R. and Prabhu, K.M. 2011. Antiatherosclerotic potential of active principle isolated from Eugenia jambolana in streptozotocin-induced diabetic rats. Evidence-Based Complementary Alternative Med. 2011.

VanWagenen, B.C., Larsen, R., Cardellina, J.H., Randazzo, D., Lidert, Z.C. and Swithenbank, C. 1993. Ulosantoin, a potent insecticide from the sponge Ulosa ruetzleri. J. Org. Chem. 58, 335-337. 